AZEVEDO, NETTO, HILLIG, v(11), no 11, p. 2273-2279, JUN, 2013.

Rev. Elet. em Gestão, Educação e Tecnologia Ambiental (e-ISSN: 2236-1170)

\title{
PERSPECTIVAS AGROECOLÓGICAS NO DESENVOLVIMENTO DE UMA COMUNIDADE RURAL: O CASO DE CERRO PELADO/URUGUAI
}

\author{
AGROECOLOGICAL PERSPECTIVE IN THE DEVELOPMENT OF A RURAL COMMUNITY: \\ THE CASE OF CERRO PELADO / URUGUAY
}

\author{
Letícia Fátima de Azevedo', Tatiane Almeida Netto², Clayton Hillig ${ }^{3}$
}

\begin{abstract}
'Mestranda do Programa de Pós Graduação em Extensão Rural - PPGExR/UFSM. E-mail: letiazevedo@ @otmail.com
${ }^{2}$ Mestranda do Programa de Pós Graduação em Extensão Rural - PPGExR/UFSM. E-mail: tatinetto@yahoo.com.br ${ }^{3}$ Docente do Programa de Pós Graduação em Extensão Rural - PPGExR/UFSM.E-mail: hillig@smail.ufsm.br
\end{abstract}

http://dx.doi.org/10.5902/223611708648

\section{RESUMO}

Nesse estudo propôs uma análise do desenvolvimento rural comunitário, tomando como referência empírica a localidade rural de Cerro Pelado localizada no Uruguai. O objetivo central é analisar sob a perspectiva agroecológica as relações socioambientais da comunidade de Cerro Pelado. Para a pesquisa foram utilizados métodos de observação direta, diário de campo, revisão bibliográfica e entrevistas semiestruturadas. As análises da agroecologia concentram esforços na dimensão comunitária em que se inserem os agricultores, isto é, a realidade sociocultural que proporciona uma práxis intelectual e política da identidade local e de sua rede de relações sociais. Cerro Pelado mostra-se integrado ao pampa, resiste ao processo de modernização através da valorização de sua cultura local e sua paisagem campestre. A integração ao pampa se observa através dos modos de produção dos agricultores familiares que utilizam a criação do gado como principal atividade, evidenciando assim sua identidade gaúcha.

Palavras-chave: agroecologia, desenvolvimento comunitário, dimensão socioambiental

\begin{abstract}
This study proposes an analysis of rural development community with reference to empirical rural locality of Cerro Pelado located in Uruguay. The main objective is to analyze the perspective of socio-environmental relations agroecological community Cerro Pelado. For the research methods used were direct observation, field journal, literature review and semi structured interviews. Analyses of agroecology focus efforts on community dimension in which they operate farmers, ie the sociocultural reality that provides an intellectual and political praxis of local identity and its network of social relations. Cerro Pelado is shown integrated with pampa, resists modernization process through the enhancement of their local culture and its countryside. The integration to the pampa is observed through the modes of production of farmers using cattle breeding as their main activity, thus revealing his identity gaucha.
\end{abstract}

Keywords: ecology, community development, environmental dimension 


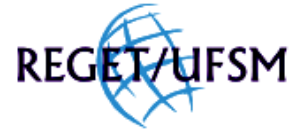

AZEVEDO, NETTO, HILLIG, v(11), no 11, p. 2273-2279, JUN, 2013.

Rev. Elet. em Gestão, Educação e Tecnologia Ambiental (e-ISSN: 2236-1170)

\section{INTRODUÇÃO}

A agricultura visualizada no contexto da corrente ecotecnocrática é vista como uma atividade tecnologicamente industrial, a margem de mecanismos bióticos que historicamente tem sido artificializado pelo homem em uma coevolução simbiótica sociedade e meio ambiente referenciando uma temática de desenvolvimento econômico (MIELGO e GUZMÁN, 1995).

Os autores acima apontam que após meados da década de 70 com o surgimento da corrente ecossocial, em reposta a preservação e manutenção da vida, dada a aceitação de que os recursos naturais sobre o planeta são limitados e finitos, deve-se assumir o controle das forças produtivas para interromper seletivamente as formas de produção degradantes de exploração e consumo.

A corrente ecossocial visualizada na temática da sustentabilidade e do desenvolvimento sustentável se alia a ciência da agroecologia, onde as mudanças na agricultura deverão se materializar no estabelecimento de formas alternativas de produção. As bases conceituais e princípios científicos da agroecologia não se limitam a obedecer apenas estímulos de mercado, mas incorporar valores ambientais e a orientação para a construção de uma nova ética de relação do homem com a natureza.

O campo é formado por diferentes territórios que exigem políticas econômicas e sociais diversas. Fernandes (2005) assinala as diferentes maneiras de pensar o campo como território ou como setor da economia, onde os sujeitos sociais executam seus projetos de vida para o desenvolvimento. Assim, compreende-se o campo como espaço de vida, no qual se manifestam e realizam as relações sociais: a educação, a cultura, a produção, o trabalho, a infraestrutura, a organização política.

O desenvolvimento rural tem como objetivo melhorar o nível de vida da população, por meio de processos de participação local e mediante potenciação de seus próprios recursos. A norma que prevalece no campo, no desenvolvimento da agricultura é de extensão a todos de uma agricultura industrializada, onde o manejo industrial dos recursos naturais é incompatível com o conceito de sustentabilidade ecológica. Casado et al. (2000) afirmam que atualmente na prática da agricultura o problema está na hegemonia das dimensões econômicas e institucionais que deixam em segundo plano o social e o ambiental.

Neste estudo é proposta uma análise do desenvolvimento rural comunitário ao tomar como referência empírica a localidade rural de Cerro Pelado no Uruguai, e a dinâmica socioambiental apresentada pela comunidade pertencente ao Departamento de Rivera. O objetivo central é analisar sob a perspectiva agroecológica as relações sócio ambientais da comunidade de Cerro Pelado.

\section{METODOLOGIA}

A presente pesquisa foi realizada na comunidade rural de Cerro Pelado/Uruguai, localizado a 76 quilômetros da sede do Departamento de Rivera/Uruguai e possui, aproximadamente, 2.000 habitantes (HARTMANN, 2011).

O ecossistema em que a localidade de Cerro Pelado está inserida, Campos Sulinos ou "Pampa", compreende regiões pastoris de planícies em três países da América do Sul - cerca de dois terços do Rio Grande do Sul (estado brasileiro), as províncias argentinas de Buenos Aires, La 


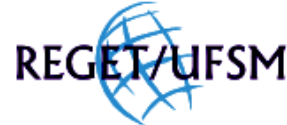

AZEVEDO, NETTO, HILLIG, v(11), no 11, p. 2273-2279, JUN, 2013.

Rev. Elet. em Gestão, Educação e Tecnologia Ambiental (e-ISSN: 2236-1170)

Pampa, Santa Fé, Entrerríos e Corrientes e a República Oriental do Uruguai (SUERTEGARAY e SILVA, 2009, p. 45).

O desenvolvimento econômico da localidade de Cerro Pelado está baseado na bovinocultura/ovinocultura de corte extensiva, valorizando a cultura e tradição pampeana. No entanto, percebe-se a adoção de culturas de grãos com baixa representatividade.

Este estudo é caracterizado por ser uma pesquisa exploratória descritiva, onde foi utilizado a abordagem metodológica de estudo de caso com intuito de análises que permitam detalhar o conhecimento para descrever a relevância socioambiental do agroecossistema do pampa.

Foram utilizados métodos de observação direta, diário de campo, revisão bibliográfica, entrevistas semiestruturadas com informantes chaves (agricultores familiares e lideranças comunitárias). A amostragem utilizada foi intencional, baseando-se em critérios empíricos que investigam um fenômeno contemporâneo em suas particularidades. O estudo de caso deve proporcionar detalhes a um levantamento que proporcionam a identificação de questões chaves (YIN, 2001; BELL, 2008).

O método de pesquisa utilizado na análise dos dados foi o qualitativo, que segundo Minayo (1994, p. 21) preocupa-se com um nível de realidade que não pode ser quantificado como "motivos, aspirações, crenças, valores e atitudes que não podem ser reduzidos à operacionalização de variáveis".

$\mathrm{Na}$ abordagem do método qualitativo utilizou-se a análise de conteúdo com propósito ir além do descrito, foi realizado uma decomposição dos dados e buscou-se as relações entre as partes decompostas. A partir das observações e diálogos, foi identificada a subjetividade dos sujeitos, com a intenção de fazer uma descrição do mundo vivido das experiências.

\section{RESULTADOS E DISCUSSÃO}

As análises sob a perspectiva agroecológica concentram esforços na dimensão comunitária em que se inserem os agricultores, isto é, a realidade sociocultural que proporciona uma práxis intelectual e política da identidade local e de sua rede de relações sociais. Isso requer amplas relações institucionais (públicas, privadas e terceiro setor) para promover o sinergismo entre as políticas públicas, com vistas a obter soluções mais integrais ou mais ampliadas dos problemas.

A agroecologia possui uma dimensão sociológica ainda que parta da análise da unidade de produção em sua dimensão técnica pretende, sobretudo, entender as múltiplas formas de dependência que o funcionamento da política, da economia e a sociedade geram sobre os agricultores. A partir daí, as análises da agroecologia concentram esforços na dimensão comunitária em que se inserem os agricultores, isto é, a realidade sociocultural que proporciona uma práxis intelectual e política da identidade local e de sua rede de relações sociais (COSTA GOMES e BORBA, 2004).

Observou-se que na relação comunitária da localidade de Cerro Pelado a realidade sociocultural permite a formação de uma rede para discussão dos problemas locais, de modo participativo e integrado aos diferentes sistemas, públicos e privados. Essa relação comunitária 


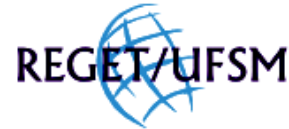

AZEVEDO, NETTO, HILLIG, v(11), no 11, p. 2273-2279, JUN, 2013.

Rev. Elet. em Gestão, Educação e Tecnologia Ambiental (e-ISSN: 2236-1170)

remete o momento da idealização e fundação do Grupo "El Fogon" da Cooperativa Mil Rancho e do salão comunal.

O Grupo El fogon e a cooperativa Mil Rancho foram criados e idealizados por Thomazio, o qual propunha uma nova forma de organização social, na qual todos teriam as mesmas responsabilidades e lutariam por um objetivo em comum, que seria o desenvolvimento da comunidade. Thomazito, como era conhecido, era o detentor das terras e acreditava em um ideal político pela igualdade, solidariedade, perseverança e equidade social.

Olhando para a comunidade de Cerro Pelado hoje, pode-se observar que as metas traçadas pelo grupo El Fogon não foram somente alcançadas, mas também, adotadas como uma filosofia ou modo de vida a ser seguido pela população, de maneira a buscar novas alternativas que levem ao desenvolvimento econômico e social da comunidade. O espírito comunitário de igualdade e perseverança foi provado no momento em que o salão comunal de Cerro Pelado foi leiloado em decorrências de dívidas assumidas com o governo, a comunidade se uniu e foi ao leilão readquirir seu imóvel.

Ainda podemos destacar a estrutura física da comunidade, que é de fundamental importância para que todos esses ideais se desenvolvessem, pois, a escola, o posto policial, o posto de saúde, as moradias e as outras estruturas que lá existem, possibilitam aos moradores a realização de seus afazeres na comunidade, e assim a interação das pessoas com o espaço rural ganha maior proporção e eleva a chance das pessoas continuarem a viver na comunidade.

Ressalta-se que a população está organizada em forma de comissões específicas onde discutem temáticas, como: educação, água, estradas, moradias e segurança. Essa forma de autogestão promove a participação, discussão e requisição às autoridades facilitando o acesso ao microcrédito e consequentemente o desenvolvimento.

Muito ganho é obtido através da organização de uma comissão com discussão conjunta e requisição às autoridades. Prova disso, foi a construção das 100 casas de vivenda próxima ao salão comunal, construções essas realizadas através de projetos governamentais aos qual a comunidade está sempre se integrando visando melhorias para a sua infraestrutura e bem estar.

O trabalho a nível comunitário é o mecanismo para instruir a organização comunitária, dotá-la de habilidades básicas, facilitando a participação local, mas essa articulação não tem como estar desvinculada de uma máquina administrativa governamental que obriga a comunidade a depender de uma ajuda técnica externa. As reuniões comunitárias acabam por se adequar as pautas convencionais do comportamento burocrático, o que faz com que reduzam o enfoque participativo. (CASADO et al., 2000).

A localidade de Cerro Pelado também participa do projeto de Produção Responsável, inserido no Manejo Integrado dos Recursos Naturais e da Biodiversidade (MVOTMA, 2010, p. 29). Este projeto tem apoio do Banco Mundial, Fundo para o Meio Ambiente Mundial e da FAO, e tem por objetivo "promover a adoção de sistemas de manejo integrado e eficiente dos recursos naturais de uso agropecuário, incluindo a diversidade biológica, que sejam econômica e ambientalmente viáveis" (MGAP, 2010, p. 11). Esse objetivo é buscado através de estímulos aos pequenos e médios agricultores e pecuaristas, principalmente, para que estes utilizem sistemas de produção sustentáveis e incorporem melhorias tecnológicas no manejo dos solos, água e diversidade biológica.

Outro exemplo da organização e ganhos para a comunidade através das comissões locais foi à construção de um poço artesiano, com auxílio de energia, pela OSE - Obras Sanitárias del 


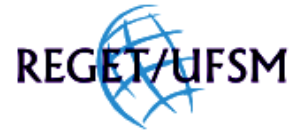

AZEVEDO, NETTO, HILLIG, v(11), no 11, p. 2273-2279, JUN, 2013.

Rev. Elet. em Gestão, Educação e Tecnologia Ambiental (e-ISSN: 2236-1170)

Estado. A localidade de Cerro Pelado foi bastante afetada pela estiagem no ano de 2009 no Uruguai, e a consequente falta de água é um problema que afeta as necessidades básicas humanas como também o cultivo e manutenção agrícola e pecuária.

Na sede da localidade de Cerro Pelado se verifica o cultivo das tradições e costumes, é exemplo das muitas funções do rural, um lugar para morar, estudar, trabalhar e recrear, ter saúde e educação, onde os moradores se articulam na organização social e política para garantia de seus direitos como educação, saúde e mais recentemente o uso sustentável dos recursos naturais. Essa forma de autogestão promove a participação social dos sujeitos envolvidos e a discussão que resulta no desenvolvimento local, social, ambiental, cultural e econômico.

Conforme destaca Casado et al. (2000) só pode alcançar o desenvolvimento com uma estrutura básica em nível de: comunidade, educação, saúde e comércio, de forma que haja integração entre a agricultura e o desenvolvimento de outros setores. Essa forma de gestão comunitária está presente em Cerro Pelado a pelo menos 40 anos.

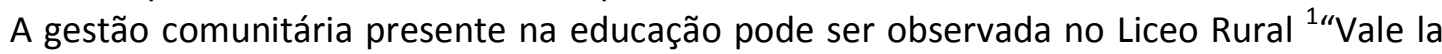
pena", onde as atividades na escola são integradas a vivência comunitária. No projeto da comunidade escolar de Cerro Pelado, os estudantes recebem papel central, participam e constroem a maioria dos espaços escolares. A comunidade escolar desenvolve um trabalho que reflete a mesma capacidade coletiva comunitária, assim, o envolvimento dos diversos atores que contribuem para formar a dinâmica escolar tem sido essencial para configurar um sistema educacional organizado pela integração entre docentes, estudantes, pais, funcionários e a comunidade de forma geral, contudo, prezando pela autonomia.

Também verifica-se a gestão comunitária junto à rádio El Chasque, um meio de comunicação que propõe refletir e discutir os problemas específicos da comunidade. A rádio possui grande audiência, principalmente em um programa criado pelos alunos, denominado de "bagualidade extrema", a qual engloba temáticas da cultura e da tradição pampeana.

El Chasque es "una radio jóven dirigida por jóvenes" abocada a acercar a toda la región noticas, cultura, información y formación general. colabora permanentemente con las entidades públicas dando apoyo y difusión a las actividades que éstas impulsan, especialmente las escuelas rurales (EL CHASQUE - FM 91.9 MHz ESTÉREO).

Observa-se que as Criollas ${ }^{2}$ de Cerro Pelado, realizada em agosto de 2011, teve finalidade de arrecadar fundos para a manutenção da policlínica local. Desta forma, as festas ocupam um importante papel na organização comunitária (HARTMANN, 2011).

As formas de relação comunitária existente na localidade de Cerro Pelado permitem a criação de resistência a modernização, se for analisado o desenvolvimento com base na agroecologia, observa-se os costumes e a tradição local, a criação extensiva de gado em campo nativo e os esquemas de desenvolvimento rural definida na autogestão participativa pela própria identidade local do etnoecossistema em que se encontra inserida, o pampa.

O conceito de desenvolvimento rural, determinado desde a agroecologia, é baseado no descobrimento, sistematização, análise e potenciação dos elementos de resistência locais do processo de modernização, para assim construir de forma participativa, esquemas de

\footnotetext{
${ }^{1}$ Escola rural de ensino fundamental. Destaca-se que este liceo é o único rural do Uruguai.

${ }^{2}$ Festa campeira tradicional que contempla a vivência e manutenção das tradições gaúchas. http://cascavel.ufsm.br/revistas/ojs-2.2.2/index.php/reget
} 


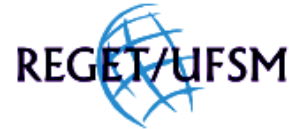

AZEVEDO, NETTO, HILLIG, v(11), no 11, p. 2273-2279, JUN, 2013.

Rev. Elet. em Gestão, Educação e Tecnologia Ambiental (e-ISSN: 2236-1170)

desenvolvimento determinados desde a própria identidade local do etnoecossistema concreto em que nos encontramos (CASADO et al., 2000).

Nesse sentido, segundo os autores a agroecologia é vista como "manejo ecológico" (enfoque científico) dos recursos naturais para constituir os métodos de desenvolvimento endógeno. O desenvolvimento endógeno se dará através da participação, na potencialização das formas de ação social coletiva que possuam um potencial endógeno transformador. Não se trata de levar soluções às localidades e sim de detectar aquelas que ali existem e acompanhar os processos de transformação existentes em uma dinâmica participativa, sendo este o núcleo do planejamento teórico e metodológico do desenvolvimento sustentável pautado na agroecologia.

O desenvolvimento comunitário pode ser compreendido a partir da perspectiva agroecológica, tendo em vista a estratégia participativa no nível de uma comunidade rural. A organização comunitária promove a busca consciência sócio ambiental e a educação, para obter uma ação social coletiva que satisfaça as necessidades básicas da comunidade.

Ao longo do século XIX o pampa sofreu alterações de paisagem com a implantação de novas culturas, tais como arroz, trigo e soja e com a introdução de indústrias como os frigoríficos (SCHWANZ, 2010). O mesmo autor relata que com a intensificação da Revolução Verde foram inseridas novas práticas agrícolas, prevendo a especialização e agravando os problemas socioambientais, onde as áreas de campo nativo foram aradas e o solo alterado em sua composição química para se adequar as novas culturas exóticas, agravando os riscos de contaminação ambiental por agrotóxicos e a perda de biodiversidade.

Atualmente se visualiza no pampa a alteração na paisagem com a introdução da silvicultura. Considerando a expansão da silvicultura no Departamento de Rivera, ressalta-se que os campos nativos ainda caracterizam a paisagem natural na localidade de Cerro Pelado. A comunidade tem receio e até certa repulsa na adoção de plantio de monocultivos de eucaliptos e pinus. A questão ambiental tem uma grande importância para a população local, uma vez que preservam a vegetação natural (fonte principal de nutrição para os animais), além de possuírem a perspectiva de desenvolvimento comunitário.

A prática comunitária no planejamento e na adoção de alternativas para o desenvolvimento de Cerro Pelado permite que não se exclua a tradição e a cultura, contribuindo assim para o fortalecimento socioeconômico e das tradições do pampa, promovendo o desenvolvimento regional sustentável.

\section{CONCLUSÕES}

A localidade de Cerro Pelado apresenta economia baseada na produção agropecuária (criação extensiva de bovino de corte e grãos). Especificamente, a criação extensiva de bovinos em campo nativo representa a imagem da cultura gaúcha, caracterizada como a identidade do povo gaúcho.

Através da dimensão sociológica que a agroecologia permite, foi desenhada uma análise da localidade de Cerro Pelado permitindo entender as múltiplas formas de dependência que o funcionamento da política, da economia e da sociedade gera sobre os agricultores, onde estes concentram esforços na dimensão comunitária na realidade sociocultural que proporciona uma práxis intelectual e política da identidade local e de sua rede de relações sociais. 


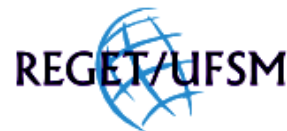

AZEVEDO, NETTO, HILLIG, v(11), no 11, p. 2273-2279, JUN, 2013.

Rev. Elet. em Gestão, Educação e Tecnologia Ambiental (e-ISSN: 2236-1170)

A localidade de Cerro Pelado mostra-se integrada ao pampa, resiste ao processo de modernização através da valorização de sua cultura local, sua paisagem campestre. Também se percebe essa integração ao pampa através dos modos de produção dos agricultores familiares que utilizam a criação de bovino como principal atividade, evidenciando assim sua identidade gaúcha.

\section{REFERÊNCIAS BIBLIOGRÁFICAS}

BELL, J. Projeto de Pesquisa: Guia para pesquisadores iniciantes em educação, saúde e ciências sociais. Tradução Magda França Lopes, 4. ed. Porto Alegre: Artmed, 2008. 224p.

CASADO, G. G. I.; MOLINA, M. G. de; GUZMAN, E. S. (coords.). Agroecologia y desarrollo rural sostenible. In: Introduccion a la agroecologia como desarrollo rural sostenible. Ediciones Mundi-Prensa, 2000.

COSTA GOMES, J. C.; BORBA, M. Limites e possibilidades da agroecologia como base para sociedades sustentáveis. Ciência \& Ambiente, n. 29, 2004.

RÁDIO EL CHASQUE - FM 91.9 MHz ESTÉREO. Disponível em:

< https://www.facebook.com/ELCHASQUE/notes\#!/ELCHASQUE >. Acesso em: 03 fev. 2013.

FERNANDES, B . M. Os campos da pesquisa em educação do campo: espaço e território como categorias essenciais. I Encontro Nacional de Pesquisa em Educação do Campo. Brasília, 2005.

HARTMANN, L. Performances culturais: expressões de identidade nas festas da fronteira entre Brasil, Argentina e Uruguai. Etnográfica [online], v. 15, n. 2, p. 233-259, $2011 . \quad$ Disponível em: <http://www.scielo.oces.mctes.pt/pdf/etn/v15n2/v15n2a02.pdf>. Acesso em: 15 dez. 2012.

MIELGO, A. M. A.; GUZMÁN, E. S. El discurso ecotecnocrático de la sostenibilidad. In: Marín, A. C. Agricultura y Desarrollo Sostenible. Ministerio de agricultura, pesca y alimentación, 1995.

MINAYO, M. C. S. (org.); DESLANDES, S. F.; CRUZ NETO, O.; GOMES, R. Pesquisa Social: teoria, método e criatividade. Petrópolis: Vozes, 1994. p. 21.

MVOTMA. Plan de Acción Nacional em Produción y Consumo Ambientalmente Sostenible 2010-2015. 2010. Disponível em: <http://www.mvotma.gub.uy/dinama/index.php?option=com_content\&view=article\&id=872:textodel-plan\&catid=366:plan-de-produccion-y-consumo-sostenible\&ltemid=431>. Acesso em: 25 nov. 2012.

SCHWANZ. A. K. Florestamento - Desenraizamento: a transformação da paisagem nos pampas e a identidade do gaúcho. Maringá: UEM, 2010. 217f. Dissertação (Mestrado em História). Universidade Estadual de Maringá, 2010.

SUERTEGARAY, D. M. A.; SILVA, L. A. P. Tchê Pampa: histórias da natureza gaúcha. In: Campo Sulinos - conservação e uso sustentável da biodiversidade. PILLAR, V. de P., et al. [editores]. Brasília, MMA, p. 42-59, 2009.

YIN, R. K. Estudo de caso: planejamento e método. 2. ed. Porto Alegre: Bookmann, 2001. 